\title{
Misdiagnosed Injuries in the Prehospital Trauma Care: Better Training needs to be Implemented
}

\author{
${ }^{1}$ Phillipe Abreu-Reis, ${ }^{2}$ Adonis Nasr, ${ }^{3}$ Flavio Saavedra Tomasich, ${ }^{4}$ Iwan Collaco
}

\begin{abstract}
Background: It is not always that prehospital trauma life support (PHTLS) principles are applied to daily practice. Lack of training to health care providers and a high amount of patients overwhelming the system capacity may let malpractice behavior to happen. It is the aim of this study to assess injuries misdiagnosed by prehospital trauma care in a capital city in southern Brazil.
\end{abstract}

Study design: A prospective observational non-controlled study with 174 random trauma cases that were brought to a level 1 trauma center in the city of Curitiba, between May 28th and June 10th 2006. We analyzed data registered in the prehospital rescue team form. The including criteria were all patients delivered to the trauma center by ambulances. The excluding criteria were patients not transported by ambulances and those without the proper form filled out. Statistical analysis was performed using the Chi-square for discrete, and the students' t-test for continuous variables.

Results: Of the 174 patients who met the including criteria, $75 \%$ were men with a mean age of 27 -year-old. Of the 11 injuries to the neck identified in the Hospital evaluation, eight were missed by the prehospital care (OR $0.26 \mathrm{Cl} 95 \%$ 0.07-0.94). Also, only $7 / 20$ injuries to the back were identified by the PHTLS team (OR $0.32 \mathrm{CI} 95 \% 0.13-0.78$ ). Similarly, only $6 / 26$ injuries to the chest (OR $0.20 \mathrm{Cl} 95 \% 0.08-0.50$ ), $4 / 15$ to the abdomen (OR $0.24 \mathrm{Cl} 95 \% 0.08-0.76$ ), $4 / 16$ to the pelvis (OR $0.23 \mathrm{Cl} 95 \%$ $0.07-0.70$ ), $13 / 33$ to the upper body (OR $0.34 \mathrm{Cl} 95 \% 0.17-$ $0.68), 7 / 39$ to the lower body (OR $0.14 \mathrm{Cl} 95 \% 0.06-0.33$ ) and $17 / 55$ (OR $0.23 \mathrm{Cl} 95 \%$ 0.12-0.42) were correctly identified in the prehospital scenario.

Conclusion: Although it is known PHTLS principles, which save lives when applied in practice, further training and remarks to its importance is needed to fully implement efficient trauma systems. Electronic data collection shall make checklists consistently filled out, so that patient care will be improved.

Keywords: Misdiagnosed injuries, Prehospital trauma care, Prevention.

\footnotetext{
${ }^{1}$ Resident, ${ }^{2-4}$ Professor

${ }^{1}$ Department of Surgery and Orthopedics, State University of São Paulo, São Paulo, Brazil

${ }^{2-4}$ Department of Surgery, Federal University of Parana Parana, Brazil

Corresponding Author: Phillipe Abreu-Reis, Resident Department of Surgery and Orthopedics, State University of São Paulo, São Paulo, Brazil, Phone: 5514981354512, e-mail: phillipeareis@gmail.com
}

How to cite this article: Abreu-Reis P, Nasr A, Tomasich FS, Collaco I. Misdiagnosed Injuries in the Prehospital Trauma Care: Better Training needs to be Implemented. Panam J Trauma Crit Care Emerg Surg 2014;3(3):93-96.

\section{Source of support: Nil}

Conflict of interest: None

\section{RESUMO}

Introdução: Nem sempre os princípios do Suporte de Vida Pré-Hospitalar no Trauma (PHTLS) são aplicadas à prática diária. Falta de treinamento para os profissionais de saúde e uma grande quantidade de pacientes suplantando a capacidade do sistema podem permitir a prática de forma inadequada. É o objetivo deste estudo avaliar as lesões não diagnosticadas pelo atendimento pré-hospitalar em uma capital em sul do Brazil.

Métodos: Estudo não controlado prospectivo observacional com 174 casos aleatórios de trauma que foram trazidos para um centro de trauma nível 1 , na cidade de Curitiba, no período de 28 de maio e 10 de junho de 2006. Foram analisados os dados registrados na ficha de atendimento do resgate préhospitalar. Os critérios de inclusão foram todos pacientes trazidos ao centro de trauma por ambulâncias. Os critérios de exclusão foram pacientes não transportados por ambulâncias e os que não tiveram a ficha de atendimento adequadamente preenchida. A análise estatística foi realizada através do quiquadrado para variáveis não contínuas, e o teste t de student para variáveis contínuas.

Resultados: Dos 174 pacientes que preenchiam os critérios de inclusão, $75 \%$ eram homens, com idade média de 27 anos de idade. Das 11 lesões cervicais identificadas na avaliação do Hospital, oito não foram identificadas pelo atendimento préhospitalar (OR 0,26 IC 95\% 0,07-0,94). Além disso, apenas 7 de 20 ferimentos dorsais foram identificados pela equipe de PHTLS (OR 0,32 IC de 95\% 0,13-0,78). Da mesma forma, apenas 6 de 26 lesões torácicas (OR 0,20 IC 95\% 0,08-0,50), 4 de 15 abdominais (OR 0,24 IC de 95\% 0,08-0,76), 4 de 16 para a pelve (OR 0,23 IC de 95\% 0,07-0,70), 13 de 33 para membros superiores (OR 0,34 IC de 95\% 0.17- 0,68), 7 de 39 para membros inferiores (OR 0,14 IC 95\%,06-,33) e 17 de 55 (OR 0,23 IC 95\% 0,12-0,42) foram corretamente identificados no pré-hospitalar.

Conclusões: Os princípios do PHTLS, apesar de ser sabido que salvam vidas quando aplicado na prática, aperfeiçoamento e considerações a sua importância devem ser implementados integralmente para que tenhamos sistemas de trauma eficientes. Coleta de dados eletrônica pode fazer com que checklists sejam preenchidos consistentemente, de forma que o atendimento ao paciente será aperfeiçoado.

Palavras chave: Lesões não diagnosticadas, Atendimento ao trauma pré-hospitalar, Prevenção, PHTLS. 


\section{INTRODUCTION}

Trauma is an important public health problem. It is currently the third leading cause of death in Brazil and worldwide, with the majority of deaths among the economically active population (20-30 years old).

Considering Brazilian data, there were 929, 240 admissions to hospitals due to external causes and 141, 227 deaths related to trauma. ${ }^{1}$ For the five-year period 2005-2009, external causes are the third leading cause of death in Brazil (12.57\%), exceeded only by heart disease and cancer. ${ }^{2}$ This prevalence is also observed in the international literature, but mainly because of the aging process of population and the increasing incidence of cancer, those disease tend to overcome the external causes.

These data make clear the importance of preventing deaths related to external causes, especially regarding traffic accidents, which should be seen as a real problem of public health. In Brazil, south region accounts for the third place in hospital admissions ranking. ${ }^{3}$ In 2010, the state of Parana alone had more than 70,000 admissions, being $24.28 \%$ only in the city of Curitiba (capital city). ${ }^{4}$ The total number of deaths in the state was 9,491 people (1,440 at Curitiba).

In addition to the quantifiable costs spent on trauma victims' treatment, there is an important economic burden that cannot be measured in terms of useful-years lost, because of the prevalence of death among young people. ${ }^{5}$

The distribution of deaths in trauma occurs in a trimodal pattern. Half of these deaths occur in the scene due to severe injuries incompatible with life. ${ }^{6}$ Thirty percent of deaths occur in the famous 'Golden Hour' between the prehospital care and the initial treatment in the emergency room. Other deaths usually occur during the in-hospital care.

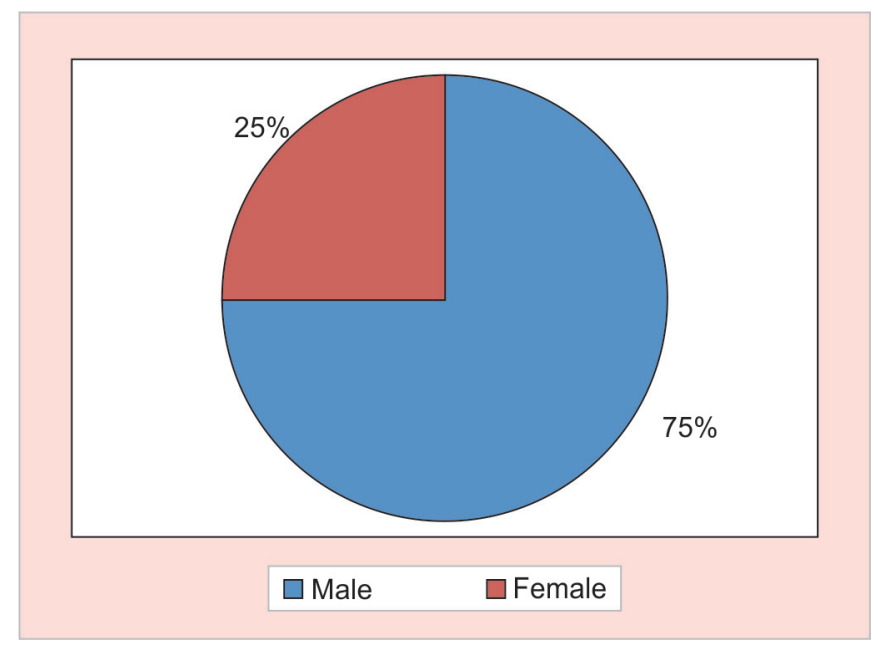

Fig. 1: Sex distribution
The first peak can only be reduced through public health preventive actions. Investments in rescue and prehospital care interfere in the second time. Finally, the in-hospital treatment will only reduce deaths from the third peak of incidence.

The Hospital do Trabalhador in the city of Curitiba, Brazil, is a well-established Level I Trauma Center. ${ }^{7}$ It has the only emergency department in the city that utilizes an 'open door system' (where the citizen can seek assistance directly) without referral by other hospitals or physicians. The Emergency Room of the Hospital do Trabalhador admitted 63,057 patients in 2010 and performed approximately 1,500 surgeries per month. This public hospital is covered exclusively by the Brazilian Unified Health System (SUS). ${ }^{8,9}$

In order to standardize the prehospital care and improve its quality, the American College of Surgeons developed through its Committee on Trauma the protocol prehospital trauma life support, (PHTLS) combining knowledge acquired in the rescue of wounded soldiers in combat to daily reality of cities.

The average time between the injury of a soldier on the battlefield to the hospital was about 90 minutes in the World War I. ${ }^{10}$ This time could be reduced to 50 minutes in the World War II, and steadily 30 minutes in the Gulf War, 20 minutes in the Vietnam War and the current 7 to 8 minutes of the wars in Afghanistan and Iraq.

The American soldier in combat sometimes receives a trauma health care with more precision and quality that civilians in big cities, where traffic does not allow any progress in terms of time to the trauma center.

Curitiba figures in this scenario as a model of capital city, with a great structure of health services, what makes the expectations of innovation to come from this city. ${ }^{11}$

The proper application of the concepts of PHTLS to daily practice may reduce mortality and morbidity related to trauma.

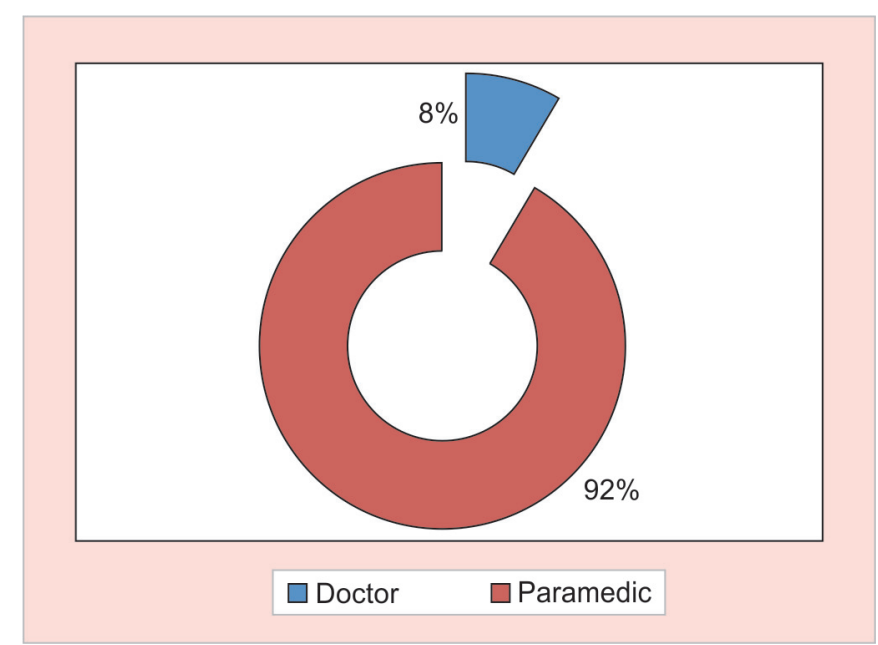

Fig. 2: Healthcare provider responsible for PHTLS 


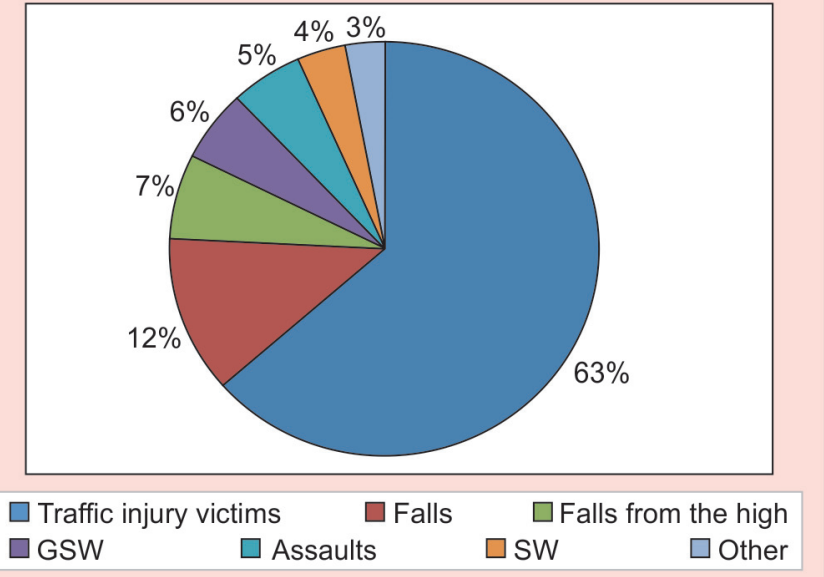

Fig. 3: Mechanisms of injury

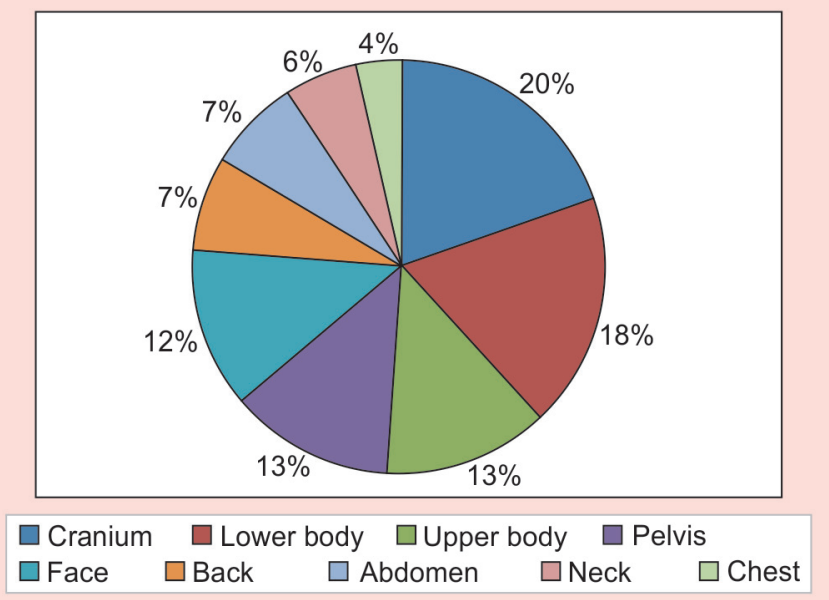

Fig. 4: Injured body parts-by segment

Table 1: Misdiagnosed injuries by segment

\begin{tabular}{|c|c|c|c|}
\hline Segment & Diagnosed (\%) & Misdiagnosed (\%) & OR \\
\hline Neck & 27 & 73 & $0.26 \mathrm{Cl} 95 \% 0.07-0.94$ \\
\hline Back & 35 & 65 & $0.32 \mathrm{Cl} 95 \% 0.13-0.78$ \\
\hline Chest & 23 & 77 & $0.20 \mathrm{Cl} 95 \% 0.08-0.50$ \\
\hline Abdomen & 27 & 73 & $0.24 \mathrm{Cl} 95 \% 0.08-0.76$ \\
\hline Pelvis & 25 & 75 & $0.23 \mathrm{Cl} 95 \% 0.07-0.70$ \\
\hline Upper body & 39 & 61 & $0.34 \mathrm{Cl} 95 \% 0.17-0.68$ \\
\hline Lower body & 18 & 82 & $0.14 \mathrm{Cl} 95 \% 0.06-0.03$ \\
\hline Head & 31 & 69 & $0.23 \mathrm{Cl} 95 \% 0.12-0.42$ \\
\hline
\end{tabular}

$\mathrm{Cl}$ : Confidence interval; OR: Odds ratio

Table 2: Common malpractices in orthopedic injuries

\begin{tabular}{llll}
\hline Suspected injury & With & Without & Absolute \\
immobilization & immobilization & number \\
\hline Closed fracture & $30 \%$ & $70 \%$ & 20 \\
Open fracture & $53 \%$ & $47 \%$ & 17 \\
Dislocations & $57 \%$ & $43 \%$ & 7 \\
\hline
\end{tabular}

Aiming to identify gaps in the implementation of the PHTLS in Curitiba city we ran the present study.

\section{METHODS OF RESEARCH}

Observational retrospective uncontrolled Study.

Data were collected from patients' medical records completed by prehospital paramedics of SIATE and SAMU and compared with the data collected by the staff of the emergency room of Hospital do Trabalhador.

All patients delivered to the trauma center between May 28 and June 10 were considered for the study. The study period was determined randomly (according to the availability of the researchers who collected data).

We included all patients delivered to the trauma center during the study period, aged over 18 years-old.

Patients younger than 18 years, patients brought by ways other than ambulance, patients who were admitted to hospital for more than 24 hours and patients who died on arrival at hospital.
Statistical analysis was performed using the Chisquare for discrete, and the students' t-test for continuous variables.

\section{RESULTS}

Of the 288 patients brought to HT on the period, 12 were excluded. The average age was 27 years old, with a prevalence in men (75\%) (Fig. 1). PHTLS was carried out by a doctor only in $8 \%$ of cases, which probably represent the most severe trauma (Fig. 2).

Regarding the mechanism of injury, there was a significant prevalence in traffic accidents, followed by falls from height and falls. Gunshot wound figured in only $6 \%$ of visits (Fig. 3).

The body segment attained in most cases was the skull, followed by the lower and upper limbs (20, 18 and 16\% respectively) (Fig. 4).

Considering cervical injuries identified in the hospital, only $27 \%$ had been suspected by PHTLS (OR 0.26 CI 95\% 0.07-0.94). Of injuries diagnosed to the back, $65 \%$ were not identified by PHTLS (OR 0.32 CI 95\% 0.13-0.78). Of thoracic injuries identified, 77\% were no found in PHTLS (OR 0.20 CI 95\% 0.08 to 12:50). Similar to this data, of abdominal injuries, 73\% were not identified in the PHTLS (OR 12.24 CI 95\% 0.08-0.76), and 75\% of pelvic injuries (OR $0.23 \mathrm{CI}$ 
$95 \%$ 0.07-0.70). Regarding to the upper limbs, $61 \%$ of the injuries were not identified (OR 0.34 CI 95\% 0.17-0.68), in the lower-body $82 \%$ of the injuries were not described (OR 0.14 CI $95 \%$ 0.06-0.33), and 69\% of head injuries were not identified (OR 0.23 CI 95\% 0.12-12.42). (Table 1).

Furthermore, $29 \%$ of patients were admitted to the hospital without cervical spine immobilization, and $35.87 \%$ without rigid board. Of the 20 patients with suspected closed fractures, $70 \%$ were taken to the hospital without immobilization. Of those with suspected fracture, $47 \%$ were transported without immobilization, and $43 \%$ of those with suspected dislocation (Table 2).

In addition to problems related to transportation, no patient data from the scene were registered in I patients' chart. Patients had no information regarding the time to hospital.

\section{DISCUSSION}

Our data show a public health problem underestimated by healthcare providers, since basic records regarding initial hemodynamic evaluation are not being recorded properly in routine medical charts.

Excess of work in hospitals sometimes explains the absence of many records in patients' chart, however in the prehospital environment the team is fully dedicated to a single patient.

Results of this study expose a critical point of prehospital trauma care: the need to adapt to existing protocols. It is known that the PHTLS if well practiced reduces mortality related to trauma, not only this but also it has a fundamental impact on the morbidity from trauma.

The lack of continued training, as well as the ignorance about the importance of details may explain this terrible fail found in our study.

Although there are patients being transported with excessive care for injuries they present, this is the cost of avoiding iatrogenic injuries. Since, the final diagnosis will only be proven in the hospital, it must be admitted that the patient has an injury until proven otherwise.

It is not acceptable that injured patients are transported improperly.

Measures of training and continuing education for rescue teams should be provided urgently to avoid iatrogenic injuries in prehospital trauma care.

Excess of work in hospitals sometimes explains the absence of many records in patients' chart, however in the prehospital environment the team is fully dedicated to a single patient.
Digital recording systems should be developed to minimize record miss-registering.

\section{REFERENCES}

1. Laing GL, Bruce JL, Aldous C, Clarke DL. The design, construction and implementation of a computerised trauma registry in a developing South African metropolitan trauma service. Injury. 2013 Jul 1. doi:pii: S0020-1383(13)00254-4. 10.1016/j.injury.2013.05.013.

2. Uemura N, Sugano K, Hiraishi H, Shimada K, Goto S, Uchiyama S, Okada Y, Origasa H, Ikeda Y. The MAGIC Study Group. Risk factor profiles, drug usage, and prevalence of aspirin-associated gastroduodenal injuries among high-risk cardiovascular Japanese patients: the results from the MAGIC study. J Gastroenterol 2014 May;49(5):814-824.

3. de Abreu RPGT, Camila N, Tabatha N, Adonis N, Saavedra TFD, Augusto CI. Guidelines for discharge: do standardized cards help in patient understanding?. Rev Col Bras Cir 2013; 40(4):335-341.

4. de Abreu RPGT, Luiza DA, da CACBA, Adonis N, Augusto CI, Saavedra TFD. Epidemiological profile of work-related accidents with biological exposure among medical students in a surgical emergency room. Rev Col Bras Cir 2013;40(4): 287-292.

5. de Abreu RPGT, Arthur C, Giana S, Adonis N, Augusto CI, Saavedra TFD. Treatment of cutaneous traumatic wounds in the emergency room:what makes difference? J Bioanal Biomed 2013;5:130-132.

6. Marttos AC, Kuchkarian FM, Abreu-Reis P, Pereira BM, Collet-Silva FS, Fraga GP. Enhancing trauma education worldwide through telemedicine. World J Emerg Surg 2012 Aug 22;7 Suppl 1:S4.

7. Abreu-Reis P, Oliveira GC, Curtarelli de Oliveira A, Sadique H, Nasr A, Saavedra Tomasich FD. Extra-curricular supervised training at an academic hospital: is 200 hours the threshold for medical students to perform well in an emergency room? World J Emerg Surg 2012 Aug 22;7 Suppl 1:S12.

8. Adonis N, Carolina T, Giana S, Iwan C, Micheli D, Phillipe AR. Prevencao ao trauma e atendimento de qualidade: uma decada de liga academica do trauma no hospital do trabalhador - UFPR (Curitiba-PR, Brasil). Pan J Trauma 2012 May-Aug;1(2):127-130.

9. Adonis N, Irene N, Valeria RA, Guilherme K, Phillipe AR. Radiologist vs Surgeon: misdiagnoses in radiologic evaluation by on-duty surgeons in the emergency room. Pan J Trauma 2012 Jan-Apr;1(1):38-43.

10. Marttos A, Kuchkarian FM, Palaios E, Rojas D, Abreu-Reis P, Schulman C. Surgical telepresence: the usability of a robotic communication platform. World J Emerg Surg 2012 Aug 22;7 Suppl 1:S11.

11. Adonis N, Flavio T, Brunol P, Marilia M, Luisa O, Helena S, Juliana C, Iwan C, Phillipe AR. Preventive peer-educational activities: what can medical students do to potentially save lives? Pan J Trauma 2012 Sep-Dec;1(3):182-185. 